Research Article

\title{
Evaluation of Waste Engine Oil-Rejuvenated Asphalt Concrete Mixtures with High RAP Content
}

\author{
A. A. Mamun $\left.{ }^{1}\right)^{1}$ and H. I. Al-Abdul Wahhab ${ }^{2}$ \\ ${ }^{1}$ Department of Civil \& Architectural Engineering, Qatar University, Doha, Qatar \\ ${ }^{2}$ Department of Civil \& Environmental Engineering, King Fahd University of Petroleum and Minerals, Dhahran, Saudi Arabia
}

Correspondence should be addressed to A. A. Mamun; amamun@qu.edu.qa

Received 30 August 2018; Accepted 7 November 2018; Published 2 December 2018

Academic Editor: Pramod Koshy

Copyright (C 2018 A. A. Mamun and H. I. Al-Abdul Wahhab. This is an open access article distributed under the Creative Commons Attribution License, which permits unrestricted use, distribution, and reproduction in any medium, provided the original work is properly cited.

\begin{abstract}
The use of large proportions of reclaimed asphalt pavement is necessary to meet the increasing demand for road construction materials in a sustainable way. One of the challenges of using a greater percentage of reclaimed asphalt pavement $(>30 \%)$ is the greater stiffness of mixes incorporating it. While this stiffness problem is usually resolved by using different commercial rejuvenators, there are circumstances in which commercial rejuvenators are not available. Therefore, this study evaluates the potential of using waste engine oil as a substitute for commercial rejuvenators for the higher percentage of reclaimed asphalt pavement that could meet the increasing demand in a more sustainable way. To assess the possibility of using a higher percentage of reclaimed asphalt pavement in road construction, different percentages of reclaimed asphalt pavement $(30 \%, 40 \%$, and $50 \%)$ are used. Following the property of the aged binder, three different percentages $(7 \%, 13 \%$, and $20 \%)$ of waste engine oil are considered. Each percent of waste engine oil is incorporated with one of the three mixes. The mixes (with the minimum required Marshall criteria) are evaluated for different properties, namely, their indirect tensile strength, resilient modulus, and durability. Finally, those properties are compared to those of the mixes rejuvenated by commercial rejuvenators. It is observed that, for the aforementioned properties, $7 \%$ to $13 \%$ of waste engine oil is identical to the commercial rejuvenator for the mixes with $30 \%$ to $40 \%$ of reclaimed asphalt pavement.
\end{abstract}

\section{Introduction}

The asphalt paving industry has had great success with recycling deteriorated asphalt pavements in the early twentieth century. The successful introduction of reclaimed asphalt pavement (RAP) in road construction has reduced the amount of virgin asphalt and aggregate needed and subsequently has made the industry's operations more sustainable. However, one of the main challenges of using RAP in road construction is the stiffness of RAP. The use of unmodified RAP can make the mix too stiff, and difficult to compact, which can result in premature failure of the pavement [1]. Increased stiffness is a consequence of gradual oxidation which alters the constituents of asphalt and consequently erodes the viscoelastic properties [2]. Therefore, to use the RAP in road construction, the lost properties of oxidized asphalt must be regained using a feasible rejuvenation technique.
Different techniques are available to overcome the stiffness of RAP, including the use of softer asphalt, a greater amount of asphalt, and warm mix technology [3]. These techniques successfully prevent stiffness by softening the aged asphalt without altering its chemical properties. However, softening techniques are only feasible to a certain extent and are not effective for greater RAP contents. But, to meet the increasing demand for materials for road construction in a sustainable way, we must use larger amounts of RAP without jeopardizing the performance of the roads. Currently, the use of rejuvenating agents has become popular, and it has proven to be a feasible alternative for a higher RAP content [4]. Unlike the softening techniques, the rejuvenating agent restores the chemical structure of aged asphalt by providing lost aromatic constituents and reduces the overall viscosity of the binder. Different types of commercial rejuvenators (CRs) have been recommended for higher percentages of RAP, especially for more than 30\% [5]. 
However, one of the challenges of using CR is its occasional lack of availability, which, along with the fluctuating availability of asphalt, can alter the cost of CR. Using different waste products as recycling agents can resolve this issue. Moreover, recycling RAP using waste products could lead to a sustainable and environmentally friendly pavement rehabilitation and recycling program.

The waste materials in asphalt pavement can be categorized following their sources, such as into (a) industrial waste, (b) municipal waste, and (c) mining waste [6]. One of the potential municipal waste materials that can be used to rejuvenate RAP is waste engine oil (WEO) from cars and trucks. The structure of WEO resembles the molecular structures of asphalt with sufficient aromatic content, which leads to coherent bonding by altering the constituents and rejuvenating the aged asphalt [7-10]. However, despite the potential of WEO to serve as a rejuvenator, very few studies evaluated WEO as a rejuvenating agent prior to 2009 [11]. Based on the studies conducted in the last ten years, it can be concluded that WEO improves several properties such as low-temperature cracking [12], fatigue resistance [13], workability [14], and temperature sensitivity [15]. It can also alter the adhesion between aggregate and asphalt [9] and reduce ductile performance [16]. A recent study concluded that WEO could provide promising performance using greater amounts of waste materials [17]. However, previous studies do not explain the extent of RAP to which WEO can be used as a rejuvenating agent.

The above discussion reveals the need for an assessment of the effectiveness of WEO as a substitute for CR for greater RAP rejuvenation. It is expected that the use of WEO as a substitute for CR for higher percentages of RAP (>30\%) can meet the growing need for road construction materials in a more sustainable way. Therefore, the study evaluates the prospect of using a higher percentage of RAP in road construction for three distinct higher percentages of WEOrejuvenated RAP. The evaluation included three different tests: indirect tensile strength (ITS), resilient modulus $\left(M_{\mathrm{R}}\right)$, and moisture susceptibility.

\section{Research Approach}

Figure 1 illustrates some of the fundamental steps applied in the study. Once the materials were collected, several basic tests were carried out. These tests were mainly for the aggregate (fresh and reclaimed) and binder (WEO, CR, and extracted binder). Based on the evaluated characteristics of the materials and following the Marshall mix design, the optimum binder contents for WEO-rejuvenated mixes were determined. The optimum binder content measurement refers to three distinct levels of binder content for three different percentages of RAP (30\%, 40\%, and 50\%). Likewise, the optimum binder content was determined for CRrejuvenated mixes. The scope of the study considered RAP up to $50 \%$, as the present plant system can only accommodate till this limit without substantial adjustment to the equipment [18]. To determine the effectiveness of these RAP-incorporated mixes, a standard mix (SM) without any RAP was also included. All the mixes were further prepared for three different evaluations: indirect tensile strength, resilient modulus, and durability tests. Finally, the effectiveness of WEO was compared with that of the CRrejuvenated mix and SM. Further elaboration of the research approach is provided in the following sections.

\section{Materials}

3.1. Aggregate and RAP. The aggregate and RAP were collected from the eastern province of Saudi Arabia. Different basic properties of the aggregate were evaluated following the standard procedures, and the results are listed in Table 1. Similar tests were performed on the RAP after it passed the ignition test (ASTM D6307). The ignition test revealed that, for an aggregate-correction factor $\left(C_{\mathrm{F}}\right)$ value of 1.2 , the amount of asphalt in the RAP was 5\%. The absolute viscosity of the reclaimed asphalt obtained following the solvent extraction method (ASTM D2172) was 43,000 poises.

3.2. Asphalt and Rejuvenator. The asphalt was collected from the Ras Tanura oil refinery and evaluated for viscosity and specific gravity (Table 2 ). The viscosity and specific gravity were measured following the standard methods ASTM D4402 and ASTM D70, respectively. Similar properties of WEO, and a CR (SAE-10 oil), that were collected from the eastern province of Saudi Arabia are tabulated in Table 2.

The amounts of WEO and CR required to be added to the mix were obtained from the blending chart. WEO and the relationship obtained from the blending chart dictated that, to obtain the target viscosity of fresh asphalt, $13 \%$ of WEO by weight of the total reclaimed binder was required. In addition to the obtained percentage, two different percentages of WEO (7\% and $20 \%$ ) were included to determine the effect of different levels of WEO in the mixes. A similar relationship indicated that $7 \%$ of CR (by weight of the total reclaimed binder) was needed for the rejuvenation.

3.3. Aggregate Blending. Table 3 summarizes the gradations for all the mixes. It was concluded that the RAP to be used in the mix should be sufficiently coarse [19], and the virgin aggregate should be adjusted with the RAP to meet the desired gradation of the mix [20]. Therefore, the coarse RAPs were adjusted with different portions of fresh aggregate following the specification constraints (Table 3 ). The mixes with three different percentages of RAP are adjusted to a desired gradation of the mix without any RAP. The final gradation follows the specification of the Ministry of Transportation, Saudi Arabia.

\section{Preparation of Samples}

Three different mixes were prepared following the Marshall mix design (ASTM D1559). One set of samples without any RAP was prepared as the standard mix, denoted as SM. Two other sets of samples rejuvenated by CR and WEO were denoted as CM and WM, respectively. The SM and WM included RAP, the required amounts of the corresponding rejuvenator, different amounts of the fresh aggregate, and 


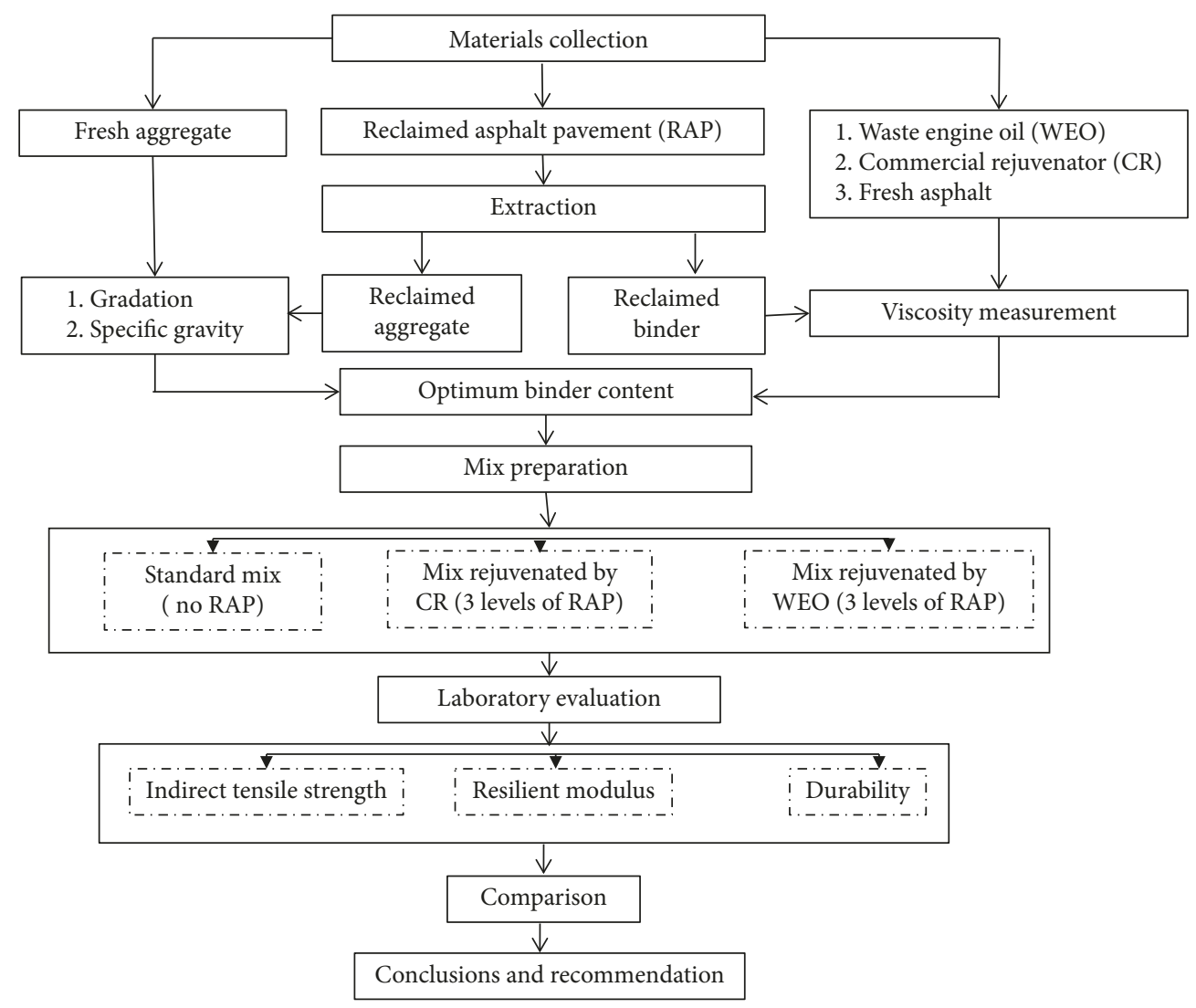

FIGURE 1: Research approach flow chart.

TABle 1: Aggregate properties.

\begin{tabular}{lcc}
\hline Property & Fresh aggregate & RAP \\
\hline Bulk specific gravity $(\mathrm{gm} / \mathrm{cc})$ & & \\
Coarse & 2.503 & 2.425 \\
Fine & 2.53 & 2.575 \\
Apparent specific gravity $(\mathrm{gm} / \mathrm{cc})$ & \\
Coarse & 2.678 & - \\
Fine & 2.575 & - \\
\hline
\end{tabular}

TABLE 2: Binder properties.

\begin{tabular}{|c|c|c|c|}
\hline Property & $\begin{array}{c}\text { Viscosity } \\
\text { (centipoise) }\end{array}$ & $\begin{array}{l}\text { Specific } \\
\text { gravity } \\
(\mathrm{gm} / \mathrm{cc})\end{array}$ & $\begin{array}{c}\text { Performance } \\
\text { grade }\end{array}$ \\
\hline Fresh asphalt & 500 & 1.017 & $64-22$ \\
\hline Waste engine oil & 50 & 0.872 & - \\
\hline $\begin{array}{l}\text { Commercial } \\
\text { rejuvenator }\end{array}$ & 37.15 & 0.860 & - \\
\hline
\end{tabular}

asphalt based on the percentage of RAP in the mix. The preparation of samples is summarized below.

4.1. Mix Design. First, prior to mixing, the RAP and fresh aggregate were heated separately for a period of two hours, at a temperature of $146^{\circ} \mathrm{C}$. The RAP was heated in a covered pan, and after two hours, all of the ingredients were placed in an automatic mixer. Once the RAP and aggregate were blended homogeneously, the mix was placed in an oven at $130^{\circ} \mathrm{C}$ for 30 minutes. Finally, it was compacted with a Marshall hammer with 75 strokes on each side. The different properties obtained from the evaluation are listed in Table 4. The optimum asphalt content was determined by evaluating the average numerical values of the observed asphalt contents for maximum density, maximum stability, and $4 \%$ of air voids. The differences in optimum asphalt levels for WM and CM were very insignificant. Therefore, the optimum asphalt level was kept similar for a specific percentage of RAP, which is named "used asphalt" in Table 4.

Table 4 indicates that all the WM and CM samples met the specifications for stability and flow value. As the increment of RAP in the mixes resulted in an increase in the stiffness, a decreasing trend in the flow value was observed due to the increased RAP content for both rejuvenators. In addition to these tests, the loss of stability was measured and found to be satisfactory for all the mixes, with the exception of CM with $50 \%$ of RAP, although the difference was insignificant. Therefore, it can be inferred that all the WM and CM samples met the specification constraints. Here, the percentages of WEO and CM used in the mixes were $13 \%$ and $7 \%$, respectively.

4.2. Laboratory Evaluation. Once the optimum level of asphalt was determined, the samples were prepared for further evaluation. Although the rejuvenated mixes (CM and WM) contained similar percentages of RAP (30\%, 40\%, and $50 \%$ ), they had different levels of rejuvenator. As stated 
TABle 3: Gradation of aggregate.

\begin{tabular}{lcccc}
\hline $\begin{array}{l}\text { 2-5 sieve } \\
\text { size }\end{array}$ & RAP & $\begin{array}{c}\text { Percentage passing } \\
\text { Reclaimed } \\
\text { aggregate }\end{array}$ & $\begin{array}{c}\text { Final (for all } \\
\text { the mixes) }\end{array}$ & Specification \\
\hline No. 3/4 & 100 & 100 & 100 & 100 \\
No. $1 / 2$ & 15.00 & 72.22 & 85.83 & $76.00-92.00$ \\
No. $3 / 8$ & 5.00 & 40.28 & 69.58 & $64.00-79.00$ \\
No. 4 & 0.00 & 12.50 & 50.00 & $41.00-56.00$ \\
No. 10 & 0.00 & 6.67 & 32.92 & $23.00-37.00$ \\
No. 40 & 0.00 & 4.44 & 18.33 & $7.00-20.00$ \\
No. 80 & 0.00 & 2.22 & 11.67 & $5.00-13.00$ \\
No. 200 & 0.00 & 0.50 & 6.50 & $3.00-8.00$ \\
\hline
\end{tabular}

above, WM had three levels (7\%, 13\%, and 20\%), whereas CM had one level (7\%). The evaluation process included three different tests: indirect tensile strength, resilient modulus, and durability tests, and the results are provided below.

4.2.1. Indirect Tensile Strength (ITS). The tensile properties of hot mix asphalt (HMA) are of interest to pavement engineers because of the problems associated with cracking. Although HMA has a higher compression-resisting capacity compared to tension, the indirect tensile strength (ITS) is a significant indication of the cracking properties of the pavement. A higher ITS value indicates a higher resistance to low-temperature cracking [21] and fatigue cracking in asphalt pavement [22]. The presence of RAP in HMA has been found to increase the tensile strength $[23,24]$. Therefore, ITS evaluation is an important test for WEO-rejuvenated HMA. The evaluation was carried out following the standard method in ASTM D6931. In this test, the desired samples are kept between two loading strips (Figure 2(a)). The load is applied such that it generates a uniform stress and is sustained until the impending failure state across the diametrical axis. The load at failure is recorded and converted to ITS using the following equation:

$$
\text { ITS }=\frac{2 P}{\pi} \times t \times d,
$$

where $\pi$ is a constant and equal to $3.1416, P$ is the load at failure, and $t$ and $d$ are the thickness and diameter of the specimen, respectively.

4.2.2. Resilient Modulus $\left(M_{R}\right)$. The purpose of flexible pavement is to provide a smooth surface for vehicle movement by transferring the wheel load through different layered structures [25]. In this regard, the resilient modulus $\left(M_{\mathrm{R}}\right)$ is an important parameter to design flexible pavement, as a higher $M_{\mathrm{R}}$ value of asphalt pavement is an indication of better resistance to rutting [26, 27]. The presence of RAP in the HMA affects the value of $M_{\mathrm{R}}$ $[28,29]$. In the present study, the $M_{\mathrm{R}}$ values are measured following ASTM D7369. The evaluation was performed using a Servo-Pneumatic Universal Testing Machine at a temperature of $25^{\circ} \mathrm{C}$ (Figure 2(b)). In this machine, digitally generated waveforms are applied by the actuator that generates repeatable stress variations in test specimens by simulating the moving traffic load. This setup engenders a uniform state of tensile stresses perpendicular to the load direction. The resulting horizontal dynamic deformation across the horizontal plane of the sample is measured as the output of the test. Consequently, the specimen responds in terms of dynamic stress and corresponding strain.

4.2.3. Durability. The durability of the pavement dictates the ability to withstand the effects of different environmental conditions without further deterioration over a long period of time under traffic loads. While asphalt pavement passes its service life in different environmental conditions, moisture plays a significant role in asphalt pavement failure by altering the adhesion between asphalt binder and aggregate [30-32]. The presence of RAP in HMA can increase the resistance to moisture damage [33]; however, the inverse was also found in another study [34]. In this study, the susceptibility to moisture has been evaluated following AASHTO T283. The degree of susceptibility to moisture damage was determined by preparing a sample set. This set, which measures tensile strength in two different conditions, is divided into two subsets, and each subset comprises three samples. Three samples are kept at room temperature, and three other samples are kept at $60^{\circ} \mathrm{C}$ in water for 24 hours followed by 2 hours at $25^{\circ} \mathrm{C}$ in water and then brought to the test temperature to determine the wet (conditioned) tensile strength. The tensile strength ratio (TSR) is measured using the following equation:

$$
\mathrm{TSR}=\frac{\mathrm{ITS}_{\mathrm{wet}}}{\mathrm{ITS}_{\mathrm{dry}}},
$$

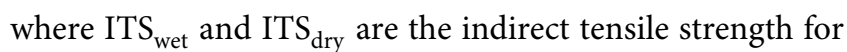
the wet and dry samples, respectively. The ratio of average wet tensile strength to average dry tensile strength should not be less than $80 \%$. In other words, the maximum loss must be $20 \%$. In the present study, durability was measured in terms of percentage of loss.

\section{Results and Discussion}

Based on the evaluation described above, the effects of different percentages of WEO for different percentages of RAP were determined, and the results are compared with those of SM and CM in the subsequent sections. The WM mixes are denoted according to the percentage of WEO. For example, WM-7 indicates that the mix comprises $7 \%$ of $\mathrm{WEO}$ and so on. All the figures represent the average value of three to six replicates with the standard deviations.

5.1. Indirect Tensile Strength (ITS). From Figure 3, it can be observed that SM has a mean ITS value of $780.38 \mathrm{kPa}$, and CM shows a mean ITS value of $657.96 \mathrm{kPa}, 787.30 \mathrm{kPa}$, and $781.36 \mathrm{kPa}$ for $30 \%, 40 \%$, and $50 \%$ of RAP, respectively.

Overall, a decrease in the ITS value is observed due to the increase in the percentage of RAP (Figure 3). Increased RAP may lead to incoherent bonding with the fresh ingredients, resulting in a less homogeneous mix and lower ITS. Figure 3 
TABLE 4: Summary of Marshall properties.

\begin{tabular}{|c|c|c|c|c|c|c|c|c|}
\hline \multirow{4}{*}{ Properties } & \multicolumn{7}{|c|}{ Mix type } & \multirow{4}{*}{ Specification } \\
\hline & \multirow{3}{*}{$\begin{array}{c}\text { Standard } \\
0 \% \\
\text { RAP }\end{array}$} & \multicolumn{3}{|c|}{ CR } & \multicolumn{3}{|c|}{ WEO } & \\
\hline & & $30 \%$ & $40 \%$ & $50 \%$ & $30 \%$ & $40 \%$ & $50 \%$ & \\
\hline & & RAP & RAP & RAP & RAP & RAP & RAP & \\
\hline Stability (kg) & 1090 & 1275 & 1150 & 1100 & 1120 & 1200 & 1100 & $800(\min )$ \\
\hline Air void (\%) & 4.2 & 4.35 & 4 & 4.2 & 4.3 & 3.95 & 4.05 & $3.0-5.0$ \\
\hline Void in mineral aggregates & 15.1 & 16.45 & 16.2 & 16.25 & 16.4 & 16.7 & 17.45 & $14(\min )$ \\
\hline Flow $(\mathrm{mm})$ & 4.15 & 3.25 & 3.75 & 2.9 & 3.3 & 3.5 & 3.3 & $2.0-4.0$ \\
\hline Void filled with asphalt & 73 & 73 & 75 & 75 & 72.5 & 77 & 77 & $70-80$ \\
\hline Stability loss (\%) & 17.77 & 22.5 & 15.7 & 18.6 & 14.98 & 9.3 & 5.02 & $20(\max )$ \\
\hline Max. unit weight $(\mathrm{gm} / \mathrm{cc})$ & 2.288 & 2.274 & 2.286 & 2.275 & 2.275 & 2.281 & 2.271 & - \\
\hline Obtained optimum asphalt & 6.1 & 5.55 & 5.15 & 5.05 & 5.59 & 5.17 & 5.08 & - \\
\hline Used asphalt & 6.1 & 5.5 & 5.2 & 5 & 5.5 & 5.2 & 5 & - \\
\hline
\end{tabular}

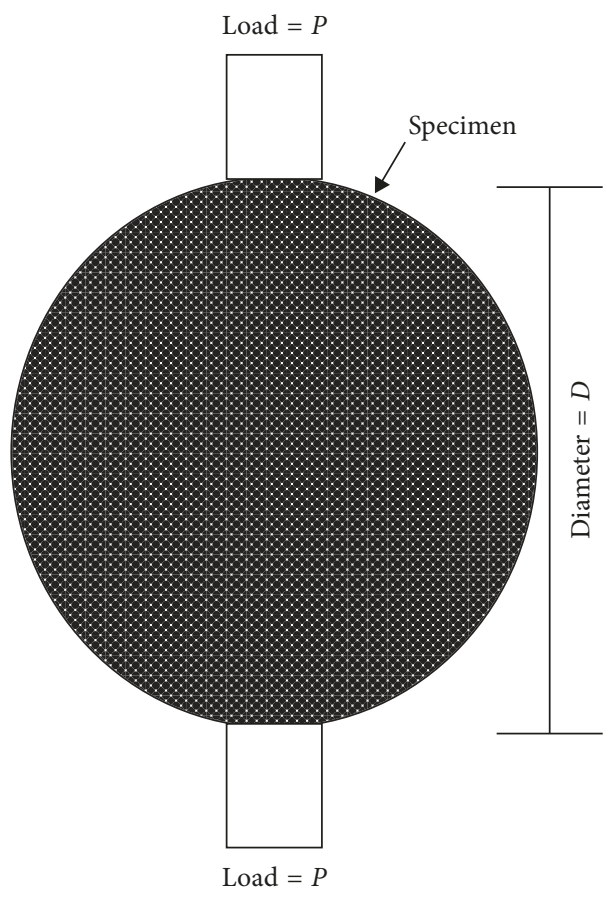

(a)

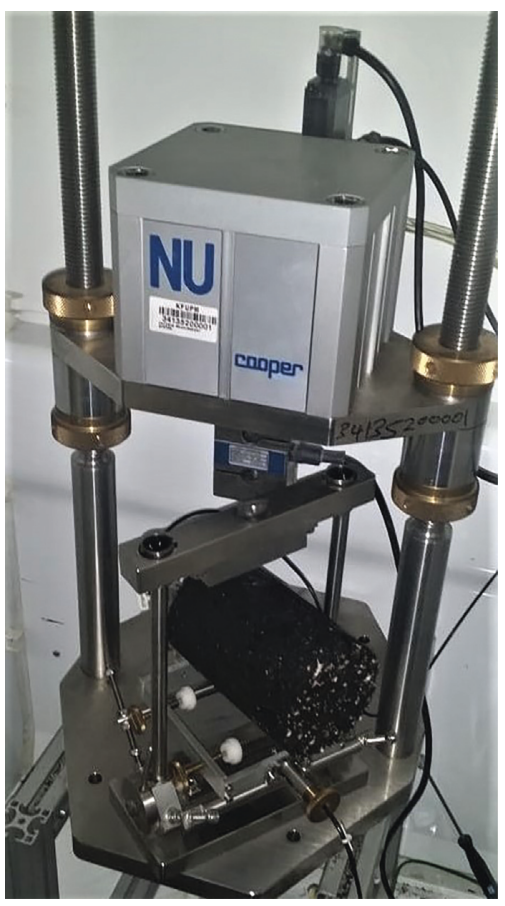

(b)

Figure 2: Experimental setup: (a) indirect tensile strength and (b) resilient modulus.

indicates that WE-7 has a mean ITS value of $860.94 \mathrm{kPa}$, $719.42 \mathrm{kPa}$, and $638.35 \mathrm{kPa}$ for $30 \%, 40 \%$, and $50 \%$ of RAP, respectively. Therefore, the $\mathrm{WE}-7$ mix shows a significant decrease in the ITS value after $40 \%$ of RAP compared to SM and CM. Here, WM-13 has a mean ITS value of $683.47 \mathrm{kPa}$, $669.28 \mathrm{kPa}$, and $644.98 \mathrm{kPa}$ for $30 \%, 40 \%$, and $50 \%$ of RAP, respectively. This indicates that WM-13 mixes after $30 \%$ of RAP show lower ITS values compared with SM and CM. A similar decreasing trend can be observed for WM-20 (Figure 3). Overall, compared with WM-7, WM-13 and WM-20 were found to have a lower ITS value for all the percentages of RAP. The increased percentage of WEO is found to have a decreasing effect on the ITS value. The increase in the percentage of WEO decreases the viscosity of the asphalt and results in a lower adhesion capacity, which can lead to lower ITS values.
5.2. Resilient Modulus $\left(M_{R}\right)$. Figure 4 illustrates the effect of the percent of RAP and WEO on the value of $M_{R}$, and the results are compared with those of SM and CM.

From Figure 4 , it can be seen that SM has a mean $M_{\mathrm{R}}$ value of $1765.33 \mathrm{MPa}$, and CM mixes have a mean $M_{\mathrm{R}}$ value of $2054.33 \mathrm{MPa}, 1998.42 \mathrm{MPa}$, and $2198.04 \mathrm{MPa}$ for $30 \%$, $40 \%$, and $50 \%$ of RAP, respectively. Here, WE-7 mixes have a mean $M_{\mathrm{R}}$ value of $1726.25 \mathrm{MPa}, 2231.08 \mathrm{MPa}$, and $1762.38 \mathrm{MPa}$ for $30 \%, 40 \%$, and $50 \%$ of RAP, respectively. The WE-7 mix shows a significant decrease in the $M_{\mathrm{R}}$ value after $40 \%$ of RAP compared with SM and CM. Figure 3 indicates a decreasing trend of the $M_{\mathrm{R}}$ value due to the increase in percentage of WEO. Overall, all the mixes showed lower $M_{\mathrm{R}}$ values than the $\mathrm{SM}$ and $\mathrm{CM}$ with the exception of WM-7 for $40 \%$ of RAP. Figure 4 also indicates an increasing pattern in $M_{\mathrm{R}}$ values due to an increase in the 


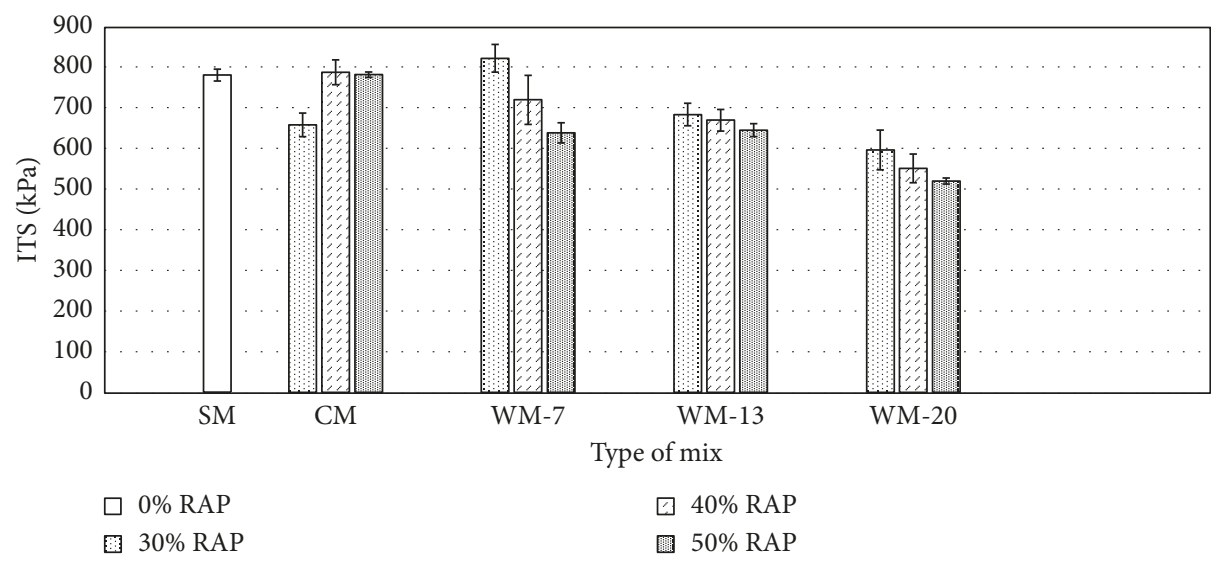

FIgURE 3: Comparison of ITS for mixes with no RAP and rejuvenated by CR with mixes rejuvenated by WEO.

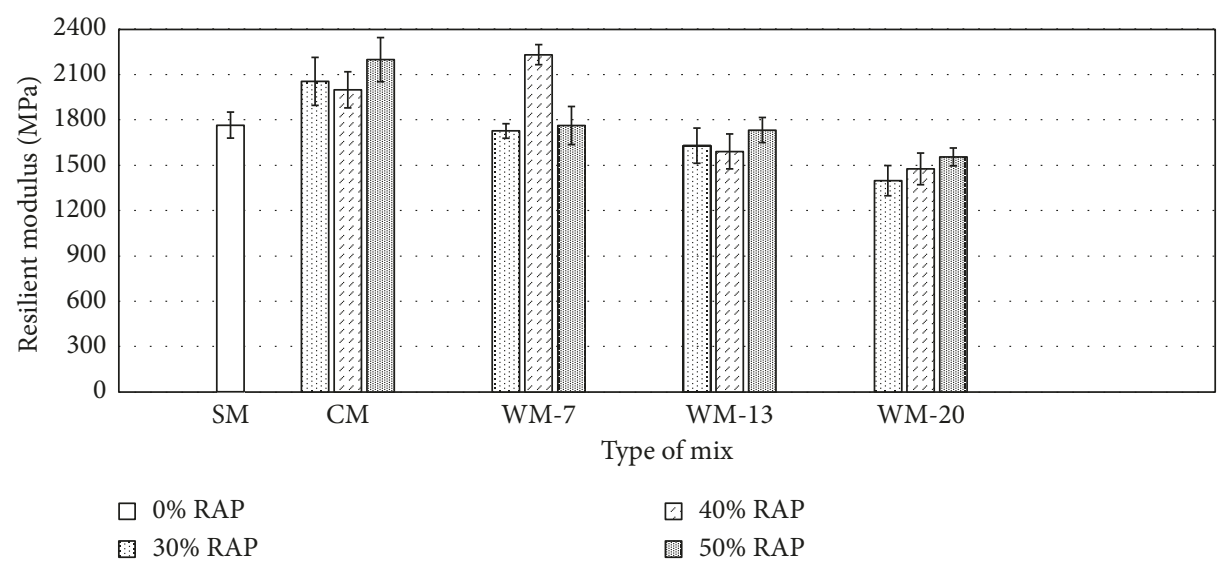

FIGURE 4: Comparison of resilient modulus for mixes with no RAP and rejuvenated by CR with mixes rejuvenated by WEO.

percentage of RAP. The increased RAP makes the mixes stiffer and consequently results in higher $M_{\mathrm{R}}$ values. However, WM-7 for 50\% of the RAP mix provides a comparatively lower value, which may be a consequence of improper mixing. A significant decrease in the $M_{\mathrm{R}}$ value is observed due to the increased percentage of WEO. The increment in the percentage of WEO results in a soft mix, and consequently, a lower value of $M_{\mathrm{R}}$ is observed. After $13 \%$ of WEO, the collective increments in RAP and WEO reveal dual effects: the softening effect of WEO and the hardening effect of RAP. However, none of the mixes rejuvenated by $20 \%$ of WEO are comparable to any of the desired mixes (SM and CM).

5.3. Durability. In Figure 5, different levels of moisture damages are observed due to the change in the percentage of RAP and WEO and compared with those of SM and CM. SM has a mean ITS loss value of $17.27 \%$, and CM mixes have a mean ITS loss value of $7.33 \%, 8.33 \%$, and $18.67 \%$ for $30 \%$, $40 \%$, and $50 \%$ of RAP, respectively.

All the mixes showed lower moisture damage than the maximum acceptable level of $20 \%$. Figure 5 indicates an increment in the trend of moisture damage due to the increment in the percentage of RAP in the mix. Higher percentages of RAP may lead to incoherent bonding with the virgin ingredients and may result in a less homogeneous mix followed by a higher percentage of moisture susceptibility. In Figure 5, it is revealed that WM-7 has a mean ITS loss value of $3.83 \%, 3.83 \%$, and $9.00 \%$ for $30 \%, 40 \%$, and $50 \%$ of RAP, respectively. All the mixes show significantly lower damage than the SM and CM. Here, WM-13 shows a mean ITS loss value of $4.00 \%, 3.17 \%$, and $9.00 \%$ for $30 \%, 40 \%$, and $50 \%$ of RAP, respectively. The observed trend is identical to that of WM-7, and it outperforms CM and SM. WM-20 with 50\% of RAP shows a significant increase in loss and exhibits a lower resistance than $30 \%$ and $40 \%$ of RAP mixes, yet it is within the specified limit. The presence of higher percentages of RAP $(>40 \%)$ and WEO (>13\%) may provide a less homogeneous mix which might lead to the mix being more susceptible to moisture damage. A similar trend has also been observed in a previous study, and it was concluded that the use of a greater amount of rejuvenator leads to a less homogeneous mix and results in higher moisture susceptibility [14]. Therefore, it can be inferred that WM-7 and WM-13 have a similar moisture resistance capacity up to the mix with $40 \%$ of RAP. 


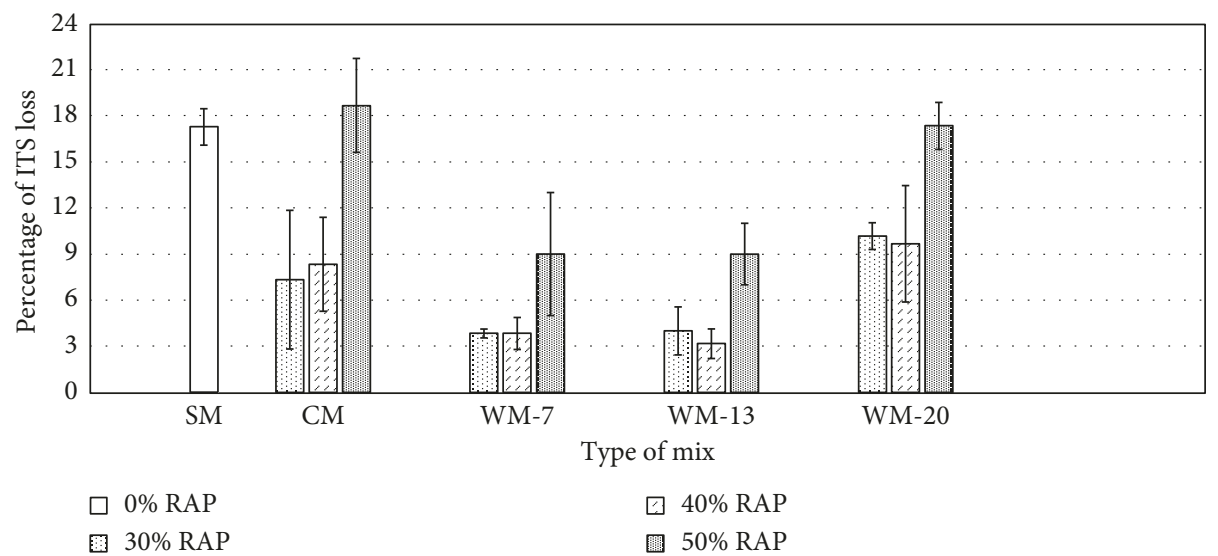

FIgURE 5: Comparison of ITS loss for mixes with no RAP and rejuvenated by CR with mixes rejuvenated by WEO.

\section{Conclusions}

In this study, different laboratory tests were conducted to evaluate the effect of WEO in rejuvenating mixes with RAP up to $50 \%$ and to compare mixes with no RAP and mixes rejuvenated by a commercial rejuvenator. Based on the results, the following conclusions can be drawn:

(1) The mixes rejuvenated by $7 \%$ of WEO have a mean ITS value of $860.94 \mathrm{kPa}$ and $719.42 \mathrm{kPa}$ for $30 \%$ and $40 \%$ of RAP, respectively, and are comparable to the mix with no RAP and the mix rejuvenated by a commercial rejuvenator. Using more than $7 \%$ of WEO in a mix with an RAP content greater than $40 \%$ results in a significant decrease in the ITS value.

(2) All the mixes rejuvenated by $7 \%$ of $\mathrm{WEO}$ are comparable to the mix with no RAP that had an $M_{\mathrm{R}}$ value of $1765.33 \mathrm{MPa}$. However, the mixes rejuvenated by $7 \%$ of WEO provide similar ITS values to the mixes rejuvenated by the commercial rejuvenator up to $40 \%$ of RAP.

(3) All the mixes (up to $50 \%$ of RAP) with $7 \%$ to $20 \%$ of WEO have lower moisture damage than the maximum permissible value of $20 \%$ and provide better moisture resistance capacity than the mix with no RAP and the mix rejuvenated by a commercial rejuvenator. However, the moisture susceptibility increases due to an increase in the percentage of RAP and WEO.

(4) Although the amalgamation of asphalt and WEO is expected to have coherent bonding, extensive scrutiny of the coherence is recommended. In such cases, different properties (e.g., adhesion and surface energy) of aged asphalt for different levels of WEO can be scrutinized using atomic force microscopy. Moreover, the results in the study refer to a source of aggregates and RAP. A comprehensive study with multiple sources of these materials is recommended for future studies.

\section{Data Availability}

The data used to support the findings of this study are available from the corresponding author upon request.

\section{Conflicts of Interest}

The authors declare that they have no conflicts of interest.

\section{Acknowledgments}

The authors would like to thank Qatar University (QU) and King Fahd University of Petroleum and Minerals (KFUPM) for their assistance in this research. The publication of this article was funded by the Qatar National Library.

\section{References}

[1] W. Mogawer, T. Bennert, J. S. Daniel, R. Bonaquist, A. Austerman, and A. Booshehrian, "Performance characteristics of plant produced high rap mixtures," Road Materials and Pavement Design, vol. 13, pp. 183-208, 2012.

[2] A. Mamun, M. Arifuzzaman, and R. Taha, "Nano scale aging characterization of carbon nanotube modified asphalt binders," in Proceedings of Advances in Materials and Pavement Prediction: Papers from the International Conference on Advances in Materials and Pavement Performance Prediction, p. 403, Doha, Qatar, April 2018.

[3] S. Im, P. Karki, and F. Zhou, "Development of new mix design method for asphalt mixtures containing rap and rejuvenators," Construction and Building Materials, vol. 115, pp. 727-734, 2016.

[4] M. Elkashef, J. Podolsky, R. C. Williams, and E. Cochran, "Preliminary examination of soybean oil derived material as a potential rejuvenator through superpave criteria and asphalt bitumen rheology," Construction and Building Materials, vol. 149, pp. 826-836, 2017.

[5] G. Mazzoni, E. Bocci, and F. Canestrari, "Influence of rejuvenators on bitumen ageing in hot recycled asphalt mixtures," Journal of Traffic and Transportation Engineering (English Edition), vol. 5, no. 3, pp. 157-168, 2018.

[6] F. Moghadas Nejad, A. Azarhoosh, and G. H. Hamedi, "Laboratory evaluation of using recycled marble aggregates on the mechanical properties of hot mix asphalt," Journal of Materials in Civil Engineering, vol. 25, no. 6, pp. 741-746, 2012.

[7] S. Fernandes, J. Peralta, J. R. Oliveira, R. C. Williams, and H. M. Silva, "Improving asphalt mixture performance by partially replacing bitumen with waste motor oil and elastomer modifiers," Applied Sciences, vol. 7, no. 8, p. 794, 2017. 
[8] I. A. Qurashi and A. K. Swamy, "Viscoelastic properties of recycled asphalt binder containing waste engine oil," Journal of Cleaner Production, vol. 182, pp. 992-1000, 2018.

[9] F. Wang, Y. Fang, Z. Chen, and H. Wei, "Effect of waste engine oil on asphalt reclaimed properties," vol. 1973, article 020012, Melville, NY, USA, June 2018.

[10] T. You, S. S. Balamurugan, M. D. Nazzal, L. N. Mohammad, I. Negulescua, and W. H. Daly, "Rheological, chemical, micromechanical, and mechanical properties of re-refined engine oil bottoms (REOB) modified binders," Technical Report, 2018.

[11] J. C. Ssempebwa and D. O. Carpenter, "The generation, use and disposal of waste crankcase oil in developing countries: a case for kampala district, Uganda," Journal of hazardous materials, vol. 161, no. 2-3, pp. 835-841, 2009.

[12] A. Villanueva, S. Ho, and L. Zanzotto, "Asphalt modification with used lubricating oil," Canadian Journal of Civil Engineering, vol. 35, no. 2, pp. 148-157, 2008.

[13] X. Jia, B. Huang, J. A. Moore, and S. Zhao, "Influence of waste engine oil on asphalt mixtures containing reclaimed asphalt pavement," Journal of Materials in Civil Engineering, vol. 27, no. 12, pp. 04015-04042, 2015.

[14] M. Zaumanis, R. B. Mallick, L. Poulikakos, and R. Frank, "Influence of six rejuvenators on the performance properties of reclaimed asphalt pavement (rap) binder and 100\% recycled asphalt mixtures," Construction and Building Materials, vol. 71, pp. 538-550, 2014.

[15] S. Liu, H. Meng, Y. Xu, and S. Zhou, "Evaluation of rheological characteristics of asphalt modified with waste engine oil (weo)," Petroleum Science and Technology, vol. 36, no. 6, pp. 475-480, 2018.

[16] Y. Qiu, H. Ding, A. Rahman, and W. Wang, "Damage characteristics of waste engine oil bottom rejuvenated asphalt binder in the non-linear range and its microstructure," Construction and Building Materials, vol. 174, pp. 202-209, 2018.

[17] S. R. Fernandes, H. M. Silva, and J. R. Oliveira, "Developing enhanced modified bitumens with waste engine oil products combined with polymers," Construction and Building Materials, vol. 160, pp. 714-724, 2018.

[18] A. Bonicelli, P. Calvi, G. Martinez-Arguelles, L. Fuentes, and F. Giustozzi, "Experimental study on the use of rejuvenators and plastomeric polymers for improving durability of high rap content asphalt mixtures," Construction and Building Materials, vol. 155, pp. 37-44, 2017.

[19] P. C. Boriack, S. W. Katicha, G. W. Flintsch, and C. R. Tomlinson, "Laboratory evaluation of asphalt concrete mixtures containing high contents of reclaimed asphalt pavement (RAP) and binder," Technical Report, Virginia Center for Transportation Innovation and Research, Charlottesville, VA, USA, 2014.

[20] R. S. McDaniel, G. A. Huber, and V. Gallivan, "Conserving resources and quality with high rap content mixes," HMAT: Hot Mix Asphalt Technology, vol. 11, no. 6, pp. 44-46, 2006.

[21] B. Huang, G. Li, and L. N. Mohammad, "Analytical modeling and experimental study of tensile strength of asphalt concrete composite at low temperatures," Composites Part B: Engineering, vol. 34, no. 8, pp. 705-714, 2003.

[22] Z. Zhang, R. Roque, B. Birgisson, and B. Sangpetngam, "Identification and verification of a suitable crack growth law (with discussion)," Journal of Association of Asphalt Paving Technologists, vol. 70, pp. 206-241, 2001.

[23] S. W. Goh and Z. You, "Mechanical properties of porous asphalt pavement materials with warm mix asphalt and rap,"
Journal of Transportation Engineering, vol. 138, no. 1, pp. 90-97, 2011.

[24] X. Shu, B. Huang, and D. Vukosavljevic, "Laboratory evaluation of fatigue characteristics of recycled asphalt mixture," Construction and Building Materials, vol. 22, no. 7, pp. 1323-1330, 2008.

[25] U. Gazder, M. Arifuzzaman, U. Shahid, and A. Mamun, "Effect of fly ash and lime as mineral filler in asphalt concrete," in Proceedings of Advances in Materials and Pavement Prediction: Papers from the International Conference on Advances in Materials and Pavement Performance Prediction, p. 373, Doha, Qatar, April 2018.

[26] B. V. Kök and H. Çolak, "Laboratory comparison of the crumb-rubber and sbs modified bitumen and hot mix asphalt," Construction and Building Materials, vol. 25, no. 8, pp. 3204-3212, 2011.

[27] N. S. Mashaan and M. R. Karim, "Evaluation of permanent deformation of crm-reinforced sma and its correlation with dynamic stiffness and dynamic creep," Scientific World Journal, vol. 2013, Article ID 981637, 7 pages, 2013.

[28] A. Mamun and H. Al-Abdul Wahhab, "Comparative laboratory evaluation of waste cooking oil rejuvenated asphalt concrete mixtures for high contents of reclaimed asphalt pavement," International Journal of Pavement Engineering, pp. 1-12, 2018.

[29] M. S. Sondag, B. A. Chadbourn, and A. Drescher, Investigation of Recycled Asphalt Pavement (RAP) Mixtures, Final Report, University of Minnesota, Minneapolis, MN, USA, 2002.

[30] M. R. Hassan, A. A. Mamun, M. I. Hossain, and M. Arifuzzaman, Moisture Damage Modeling in Lime and Chemically Modified Asphalt at Nanolevel Using Ensemble Computational Intelligence, Computational intelligence and neuroscience, vol. 2018, Article ID 7525789, 9 pages, 2018.

[31] A. Mamun and M. Arifuzzaman, "Nano-scale moisture damage evaluation of carbon nanotube-modified asphalt," Construction and Building Materials, vol. 193, pp. 268-275, 2018.

[32] A. Mamun, Abdullah, and Arifuzzaman, "Evaluation of lime performane on resisting moisture damage of elvaloy modified asphalt at nano scale (0006)," in Book of Abstracts Geomatics, p. $88,2017$.

[33] S. Zhao, B. Huang, X. Shu, and M. Woods, "Comparative evaluation of warm mix asphalt containing high percentages of reclaimed asphalt pavement," Construction and Building Materials, vol. 44, pp. 92-100, 2013.

[34] F. Moghadas Nejad, A. Azarhoosh, G. H. Hamedi, and H. Roshani, "Rutting performance prediction of warm mix asphalt containing reclaimed asphalt pavements," Road Materials and Pavement Design, vol. 15, no. 1, pp. 207-219, 2014. 


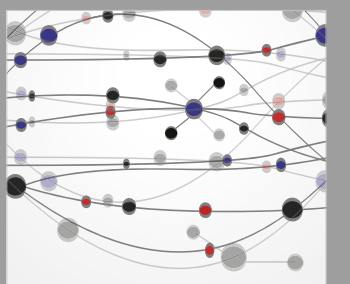

The Scientific World Journal
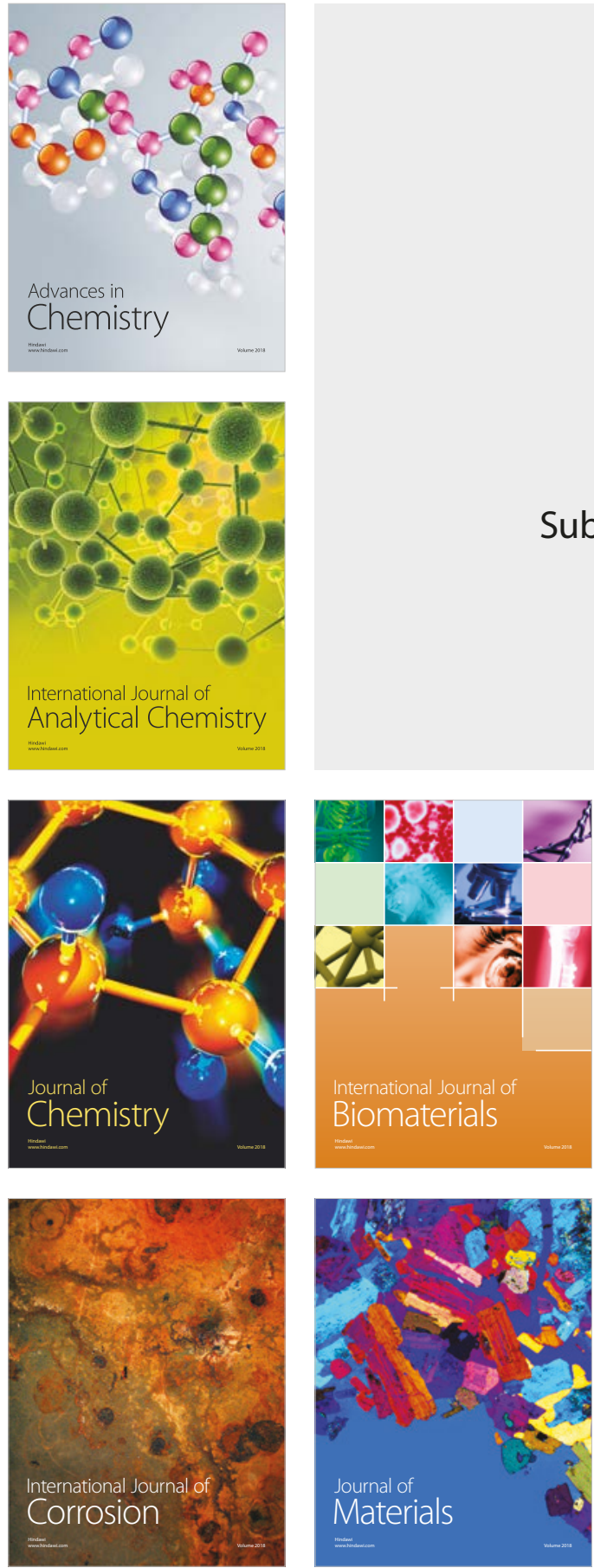

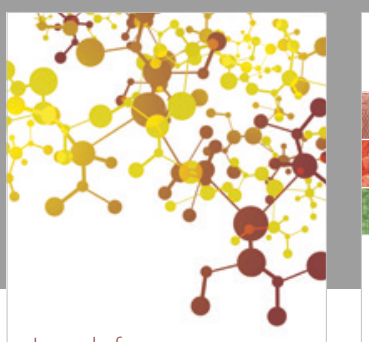

Journal of

Applied Chemistry
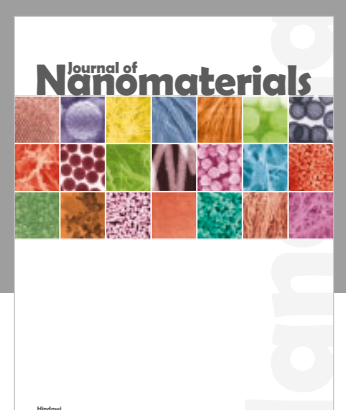

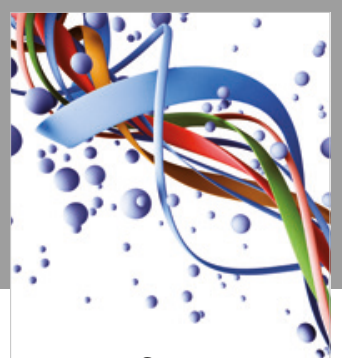

Scientifica

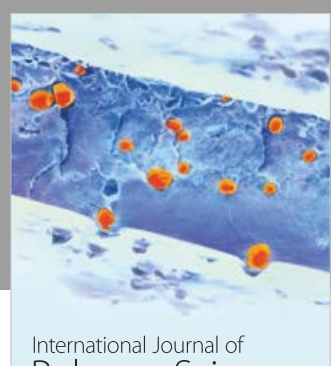

Polymer Science

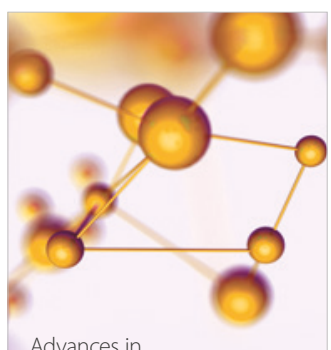

Physical Chemistry
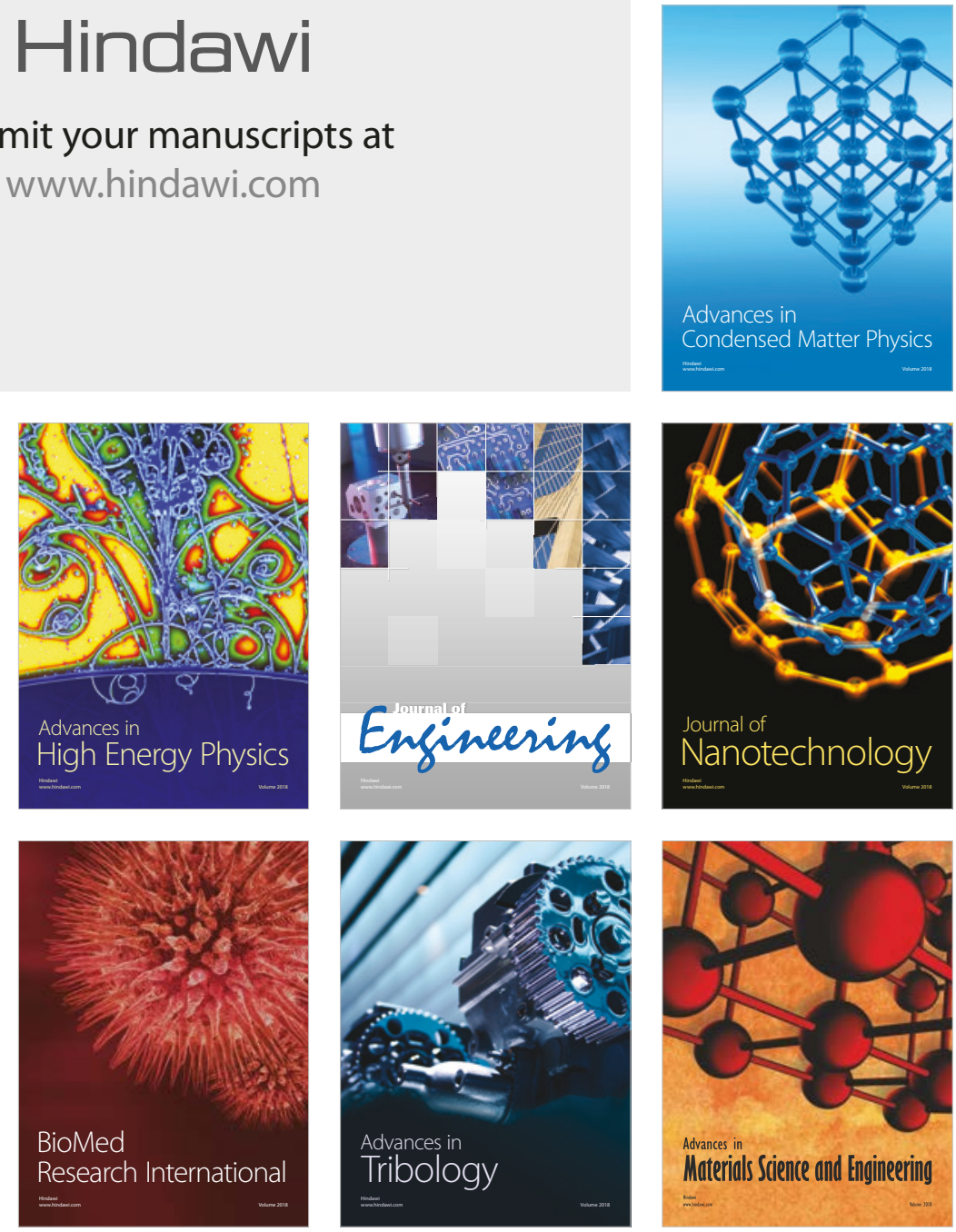